\title{
Regional distribution of pulmonary epithelial permeability in normal subjects and patients with asbestosis
}

\author{
AR GELLERT, CA LEWIS, JA LANGFORD, SEJ TOLFREE, RM RUDD \\ From the London Chest Hospital, London
}

ABSTRACT The overall and regional clearance of an inhaled isotope labelled solute from the lungs was examined on the basis of a 15 minute period of data collection, for which a technique was developed that does not require intravenous injection to correct for blood-tissue background activity. The technique was applied to 52 normal subjects ( 31 non-smokers and 21 smokers) and to 37 patients with asbestosis (21 non-smokers and 16 smokers). In normal smokers solute clearance was faster in the upper and middle zones, with a mean ratio of $T^{1 / 2} \mathrm{LB}$ (half time solute clearance from lungs to blood) in the upper two thirds to the lower one third of the lungs of 0.66 (0.28-1.33), compared with $1.24(0.43-2.77)$ in normal non-smokers $(p<0.002)$. In patients with asbestosis solute clearance was accelerated throughout the lungs even though radiographic abnormalities were limited to lower or lower and middle zones. Regional distribution of clearance was not affected by posture in normal subjects. Overall solute clearance was significantly faster in normal current smokers and in patients with asbestosis than in normal non-smokers $(p<$ 0.001 respectively). Among patients with asbestosis, smokers had faster overall clearance than non-smokers $(p<0.01$ ). Among normal non-smokers $T 1 / 2$ LB was not significantly different between those who had never smoked and ex-smokers. Regional abnormalities in pulmonary epithelial permeability may offer insight into the pathogenesis of interstitial lung diseases and smoking related disorders.

The rate of clearance of an inhaled solute from lungs to blood is thought to be an index of pulmonary epithelial permeability. ${ }^{2}$ Whereas data from clearance curves in normal non-smokers may be best fitted by a monoexponential function, it has been shown that the accelerated clearance values from patients with interstitial lung diseases and high permeability lung oedema may be resolved into two components. ${ }^{1-3}$ Jones and colleagues ${ }^{12}$ suggested that at least half of the alveoli in the scanning field had very leaky epithelial walls in such circumstances, and Pantin ${ }^{3}$ suggested that the existence of two components may be explained by the patchy nature of the disease.

We have devised a technique to examine the spatial distribution of pulmonary epithelial permeability. This allows regional numerical analysis and visual appraisal of clearance data with a display of the

Address for reprint requests: Dr RM Rudd, London Chest Hospi-

Accepted 20 May 1985 entire lung field. The technique permits correction for background tissue activity without the need for an intravenous injection of isotope, thereby reducing the radioactive load and increasing acceptability to patients.

We report results obtained with this method in normal non-smokers, in otherwise healthy current smokers, and in patients with clinical and radiographic evidence of asbestosis.

\section{Methods}

\section{PATIENTS}

We studied 37 patients with asbestosis (21 nonsmokers and 16 current smokers; mean age 57, range 32-74 years) and 52 normal subjects (31 non-smokers and 21 current smokers; mean age 39 , range 19-62 years).

The patients with asbestosis had attended an asbestos screening clinic for up to 30 years and retrospective clinical and radiographic data were available in 24 cases. Patients had been exposed to 
asbestos for a mean period of 19 (range 1-43) years, and first exposure to asbestos had occurred a mean of 35 (range 18-53) years previously. Twenty six had worked in the lagging industry and 11 had carried out asbestos cutting, milling, or spinning. Patients had been breathless for a mean of five (range 0-27) years; two were not breathless at the time of study. Objective evidence of disease had existed for a mean of 12 (range 1-25) years in the 24 patients for whom retrospective clinical data were available. All patients had crackles over the lung fields and 20 showed clubbing of the fingers.

Normal subjects had normal chest radiographs and spirometric values. In all cases non-smokers were either life long non-smokers or had ceased smoking at least two years previously. Among the 31 normal non-smokers, 23 had never smoked and eight were ex-smokers.

All subjects gave informed consent.

\section{PHYSIOLOGICAL ASSESSMENT}

The following physiological measurements were made in patients with asbestosis: forced expiratory volume in one second $\left(\mathrm{FEV}_{1}\right)$, forced vital capacity (FVC) (Morgan dry spirometer), total lung capacity (TLC) and residual volume (RV) (Morgan constant volume body plethysmograph), and carbon monoxide transfer factor (TLCO) (Morgan Transfer Test Model TTC).

\section{CHEST RADIOGRAPHS}

Standard posteroanterior chest radiographs were examined by the recruiting physician and two consultant chest physicians unacquainted with the clinical details. The extent of pleural disease and profusion of small opacities in upper, middle, and lower zones were recorded in accordance with International Labour Office criteria. ${ }^{4}$ Numerical values were assigned to the profusion of small opacities in each lung zone to facilitate examination of the relationships between radiographic profusion and the clearance of inhaled solute in the same lung zone.

\section{CLEARANCE OF ${ }^{4 m} T c$ DTPA}

The half time clearance in minutes of diethylene triamine pentacetate (DTPA) labelled with technetium $99 \mathrm{~m}\left({ }^{99 \mathrm{~m} T c}\right)$ from lungs to blood $\left(\mathrm{T}^{1 / 2} \mathrm{LB}\right)$ was measured in all individuals. An aerosol was generated from an Acorn jet nebuliser containing 20 mCi ${ }^{99 m}$ Tc DTPA in $4 \mathrm{ml}$ saline. The output was modified by passage through an array of stainless steel ball bearings to remove large particles, as described by Jones and colleagues.' A cascade impactor demonstrated that $77 \%$ of particles were less than $0.9 \mu \mathrm{m}$ and only $4 \%$ were greater than 2 $\mu \mathrm{m}$ in diameter. Subjects inhaled for five minutes from the nebuliser and retained about $5 \%$ of the radioactivity.

Data were collected over 15 minutes by means of a Siemens 37 ZLC gamma scintillation camera linked to an MDS A2 computer, which acquired the data as a series of 15 consecutive frames, each of one minute duration. Because the data were unsuitable for high resolution imaging, a coarse image matrix ( $32 \times 32$ pixels) was used.

Analysis of the data was predominantly automatic and provided both qualitative and quantitative information. On completion of the acquisition the first image in the series was displayed and three regions of interest were entered, one around each lung and a third placed between the kidneys to facilitate subtraction of blood-tissue background radioactivity. The inter-renal area was chosen because of its high vascularity and because preliminary studies had shown that the incremental increase in radioactivity in this region after an intravenous injection of ${ }^{99} \mathrm{~m} \mathrm{Tc}$ DTPA was very similar to the increase observed over the lungs. A further three regions of interest were automatically created within each lung field, producing subdivisions of the lung into upper, middle, and lower thirds.

Background corrected time-activity curves were generated individually for each third of the lung and in addition for the whole lung. A least squares fitting routine was then used to determine the single exponential decay factor from which the half time was calculated.

\section{VISUAL DISPLAY}

To enable a visual display of the clearance data to be produced, half times were also calculated from the time-activity curves of each pixel within the whole lung region. These data form a functional image of regional DTPA clearance, which is displayed according to an eight level colour scale indicating half times from 0-15 minutes (dark blue) and progressing through 15 minute increments to 105-120 minutes (red). The relatively low counts acquired per pixel, particularly in the later frames of the study, restrict the accuracy of the data forming the image, the effect of which is to add "noise" to the image arising from pixels with half times derived from poorly correlated data. In an attempt to reduce noise, pixel values associated with correlation coefficients greater than -0.5 were replaced with a four point smooth from the immediately adjacent pixels. An index of the number of pixels replaced is displayed with the image to permit an assessment of reliability.

\section{CORRECTION FOR BACKGROUND TISSUE}

ACTIVITY

In all patients correction for background bloodtissue activity was achieved by subtracting the 
counts per pixel in the background region of interest from those in the lung region of interest. In eight patients with asbestosis (five non-smokers and three smokers), eight normal non-smoking subjects, and eight normal smokers intravenous injections of 0.5 $\mathrm{mCi}$ of ${ }^{99} \mathrm{~m} \mathrm{Tc}$ DTPA were administered at the end of the 15 minute period of data acquisition; data were collected for a further five minutes and correction for background tissue activity was achieved by subtracting a proportion of the inter-renal counts from the lung counts by a method based on that described by Jones and colleagues ${ }^{1}$ for thigh counts. The increase in counts over each lung zone and over the inter-renal area after an intravenous injection was determined and a separate background correction for each zone was then made. Regional T1/2 LB values were calculated for each third of the lung by both methods of background correction. Overall and regional background corrected clearance half times obtained by our method not requiring an intravenous injection and by the method of Jones and colleagues were then compared.

\section{RESOLUTION OF CLEARANCE CURVES INTO TWO EXPONENTS}

Background corrected clearance curves from the 24 individuals referred to in the previous paragraph were subjected to a standard curve stripping procedure in an attempt to resolve the curves into more than one exponent.

\section{EFFECT OF POSTURE ON REGIONAL SOLUTE CLEARANCE}

All patients with asbestosis and all normal smokers were studied in the upright posture, seated in front of the gamma scintillation camera. Of the 31 normal non-smoking subjects, 12 were studied supine and 19 in the seated position during the 15 minutes of data acquisition to investigate any effect of posture on regional patterns of solute clearance from the lung. In addition, two normal non-smokers were studied in both the seated and the supine position on two separate occasions.

STATISTICAL ANALYSIS

The Mann-Whitney U test (two tailed) was used for group comparisons of quantitative data and the Wilcoxon signed rank test for paired data. Nonparametric statistics were used as the data were not normally distributed.

\section{Results}

PHYSIOLOGICAL MEASUREMENTS

Observed values were compared with published predicted normal values for age and height. ${ }^{s}$ The mean FEV, was 2.48 (range 1.3-3.5) l, representing a mean of $81 \%$ of the predicted normal (range 48$134 \%$ ); the mean FVC 3.62 (range $2.1-4.8$ ) 1 or $84 \%$ predicted normal $(50-113 \%)$, the mean RV $1.83(0.7-3.9) 1$ or $81 \%$ predicted normal (31$155 \%)$; the mean TLC $5.12(3.3-8.04) 1$ or $81 \%$ predicted normal (56-113\%); and the mean TLCO $6.52(3.4-11.8) \mathrm{mmol} \mathrm{min} \mathrm{m}^{-1} \mathrm{kPa}^{-1}$ or $69 \%$ predicted normal (36-123\%). Relationships between physiological variables, clinical features, and clearance of ${ }^{99 \mathrm{~m}}$ Tc DTPA are reported elsewhere. ${ }^{67}$

\section{OVERALL CLEARANCE OF ${ }^{99 \mathrm{~m}}$ Tc DTPA}

The mean overall $T^{1} 1 / 2 L B$ in normal non-smokers was 59.2 (41-101) minutes, significantly longer than $22.2(9.0-68)$ minutes in normal smokers ( $p<$ $0.001), 31.5(10-62)$ minutes in non-smokers with asbestosis $(p<0.001)$, and 20.6 (9.5-57.0) minutes in smokers with asbestosis $(p<0.001)$. Among patients with asbestosis, smokers had significantly faster clearance than non-smokers $(p<0.01)$. Of the 31 normal non-smokers, the mean $T^{1 / 2} \mathrm{LB}$ in the 23 who had never smoked was 59.8 (42.5-91.5) minutes, which was not significantly different from $57.4(41.0-101.0)$ minutes in the eight ex-smokers.

\section{REGIONAL CLEARANCE PATTERNS}

The figure shows regional clearance pictures from a normal non-smoker, a normal smoker, and a nonsmoker with asbestosis. Tables 1 and 2 show mean values of $T^{1 / 2} L B$ in each lung zone and the ratio of $T^{1 / 2} \mathrm{LB}$ in the upper two thirds to lower one third of the lungs in the various groups. Inspection of the visual displays suggested that in all otherwise healthy smokers and in many smokers with asbestosis who had non-uniform distribution of clearance the lower zones differed from the upper two zones, and the ratio of $T^{1 / 2} L B$ in the upper two thirds to $T 1 / 2 L B$ in the lower third of the lungs were therefore used for statistical analysis. In normal smokers clearance was faster in the upper parts of the lung fields than in normal non-smokers, most of whom had uniform clearance. This difference in distribution of clearance between smokers and non-smokers was seen to a lesser extent in patients with asbestosis. The distribution of clearance in non-smokers with asbestosis did not differ from that in normal non-smokers despite a large difference between the groups in overall $T 1 / 2 L B$.

\section{CHEST RADIOGRAPHS}

All cases showed radiographic profusion scores equivalent to grade $1 / 0$ or more by International Labour Office criteria and profusion scores were higher for the lower zone than the upper two zones. 


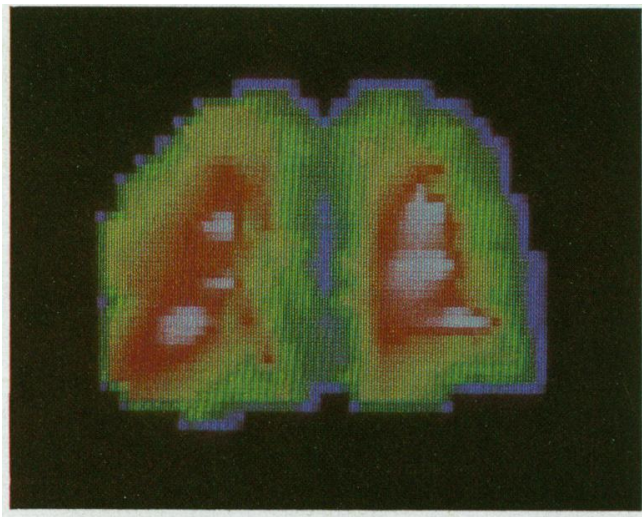

a

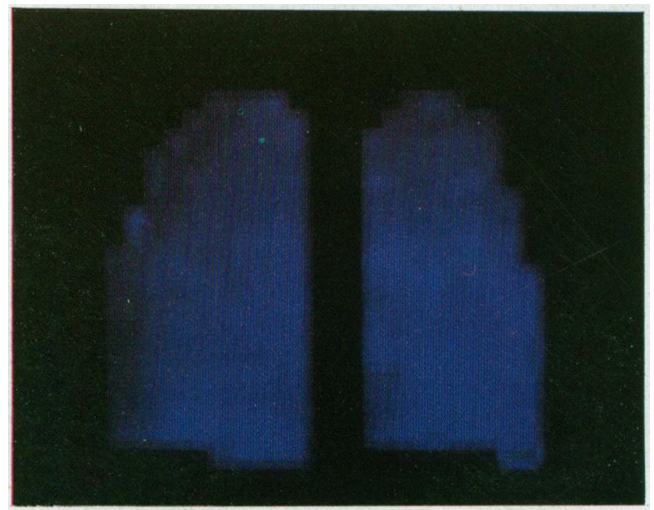

C

Table 1 Regional values for clearance $\left(T^{1} / 2 L B\right)$ in minutes expressed as means with ranges in parentheses for each lung zone

\begin{tabular}{|c|c|c|c|c|}
\hline \multirow[t]{2}{*}{ Lung zone } & \multicolumn{2}{|l|}{ Normal subjects } & \multicolumn{2}{|l|}{ Asbestosis } \\
\hline & Non-smokers & Smokers & Non-smokers & Smokers \\
\hline $\begin{array}{l}\text { Upper } \\
\text { Middle } \\
\text { Lower }\end{array}$ & $\begin{array}{l}46.7(12.0-99.0) \\
62.5(30.5-125.0) \\
53.0(22.5-117.0)\end{array}$ & $\begin{array}{l}15.3(6.0-46.5) \\
22.6(8.5-77.0) \\
29.3(11.0-79.0)\end{array}$ & $\begin{array}{l}28.4(6.5-90.5) \\
35.2(9.0-75.0) \\
26.2(10.5-66.5)\end{array}$ & $\begin{array}{l}16.2(4.5-50.5) \\
21.3(7.0-66.0) \\
21.6(5.0-53.0)\end{array}$ \\
\hline
\end{tabular}

There were no relationships between regional solute clearance and radiographic profusion scores in any lung zone or in the lung field as a whole.

\section{EFFECTS OF POSTURE}

Regional distribution of solute clearance was not affected by posture. The mean ratio of $T^{1} / 2 \mathrm{LB}$ in the upper two thirds to lower third of the lungs of 12 normal non-smoking subjects studied in the supine position was $1.21(0.6-2.39)$, not significantly different from $1.26(0.43-2.76)$ in the 19 subjects

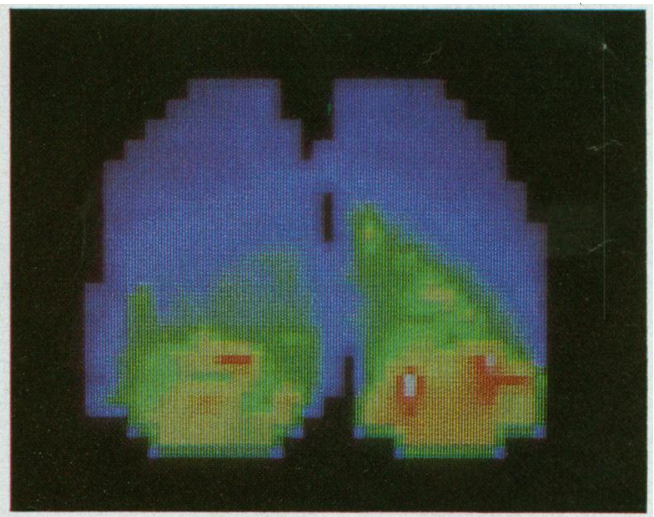

b

Regional half time clearance $\left(T^{1} 1 / 2 L B\right)$ pictures in (a) a normal non-smoking subject, illustrating homogeneously slow clearance (32\% pixels replaced); (b) an otherwise healthy current smoker with concentration of the disturbance of clearance to upper and middle zones $(17 \%$ pixels replaced); and (c) a non-smoking patient with asbestosis showing widespread disturbance of clearance (11\% pixels replaced). The displays are based on an eight level colour scale for $T 1 / 2 L B$, showing half times from $0-15$ minutes (dark blue) through 15 minute increments to 105-120 minutes (red). 
Table 2 Ratio of clearance $\left(T^{1 / 2} L B\right)$ in upper two thirds of lung fields to clearance in smoking and non-smoking normal subjects and in patients with asbestosis

$\begin{array}{llll}\hline \text { Subjects }(y) & \text { Ratio of } T 1 / 2 L B \text { in upper } 2 / 3 \text { to } T 1 / 2 L B \text { in lower } 1 / 3 \text { of lung fields } & p \\$\cline { 2 - 3 } & \text {$\left.Mean } & \text { Range } & <0.002 \\ \hline \text { Normal non-smokers (31) } & 1.24 & 0.43-2.77 \\ \text { Normal smokers (21) } & 0.66 & 0.28-1.33 & <-39-3.48 \\ \text { Asbestosis non-smokers (21) } & 1.33 & 0.34-2.20\end{array}\right\}$

ground activity was calculated both with and without data obtained after an intravenous injection are shown in table 3 . The mean differences between T $1 / 2$ LB values calculated by our method and by the method using an intravenous injection were not significant.

\section{RESOLUTION OF TIME-ACTIVITY CURVES INTO SEPARATE EXPONENTS}

Of the eight normal non-smokers studied for this purpose, six showed monoexponential clearance curves from both lungs, one showed two exponents from both lungs, and one showed two exponents from only one lung. For those lungs in which two exponents were resolved the mean $T^{1 / 2} \mathrm{LB}$ for the fast exponent was 1.6 (range 1.3-1.8) minutes contributing a mean of $7.4 \%$ (range $4.4-9.1 \%$ ) to total clearance. The mean T $1 / 2$ LB for the slow exponent was $67.3(56.8-82.0)$ minutes.

Of the eight normal smokers, four showed monoexponential clearance curves from both lungs, one showed two exponents from each lung, and three showed two exponents from one lung only. For those lungs in which two exponents were resolved the $\mathrm{T}^{1 / 2} \mathrm{LB}$ for the fast exponent was $2.9(1.2-4.5)$ minutes, contributing a mean of $21.9 \%$ (1.1$49.4 \%$ ) to total clearance; the contribution in the three subjects showing two exponents in a single lung was small (range 1.1-8.2\%), while the contribution in the single individual showing two exponents in both lungs was much greater $(44.4 \%$ and $49.4 \%$ for each lung).

Of the eight patients with asbestosis, four showed two exponents in both lungs, three showed two exponents in one lung only, and only one patient showed monoexponential curves from both lungs. For those lungs for which two exponents were resolved, the mean $\mathrm{T}^{1} / 2 \mathrm{LB}$ of the fast exponent was 4.1 (0.3-15.0) minutes contributing a mean of $29.7 \%$ (8.5-69.3\%) to total clearance; and the mean T $1 / 2 \mathrm{LB}$ of the slow exponent was $28.1(15.0-86.8)$ minutes.

\section{Discussion}

We have developed a computer assisted technique for assessing the spatial distribution. of changes in pulmonary epithelial permeability. Attempts have been made to examine regional differences in permeability. Mason and colleagues ${ }^{8}$ and Rinderknecht and colleagues 9 attempted to develop a procedure for evaluating regional permeability; but their technique relied on the comparison of a scintiscan obtained at the end of isotope inhalation with

Table 3 Overall and regional clearance $\left(T^{1} 1 / 2 L B\right)$ in minutes from upper, middle, and lower zones with background correction carried out without and with an intravenous injection in eight normal non-smokers, eight normal smokers, and eight patients with asbestosis (data collected in the upright posture)

\begin{tabular}{|c|c|c|c|}
\hline \multirow[t]{2}{*}{ Subjects and zones } & \multicolumn{2}{|l|}{$T 1 / 2 L B(\min )$ (mean (range)) } & \multirow[t]{2}{*}{ Mean difference (SEM) } \\
\hline & Without intravenous injection & With intravenous injection & \\
\hline $\begin{array}{l}\text { NORMAL NON-SMOKERS } \\
\text { Overall } \\
\text { Upper zones } \\
\text { Middle zones } \\
\text { Lower zones }\end{array}$ & $\begin{array}{l}61.4(53.0-73.0) \\
55.3(26.0-116.0) \\
95.6(54.5-177.0) \\
59.4(24.0-138.0)\end{array}$ & $\begin{array}{l}63.3(50.0-76.5) \\
59.4(29.5-131.0) \\
98.9(57.0-192.0) \\
61.7(20.0-155.0)\end{array}$ & $\begin{array}{l}1.9(1.5) \\
4.1(2.9) \\
3.3(3.7) \\
2.3(2.2)\end{array}$ \\
\hline $\begin{array}{l}\text { NORMAL SMOKERS } \\
\text { Overall } \\
\text { Upper zones } \\
\text { Middle zones } \\
\text { Lower zones }\end{array}$ & $\begin{array}{l}27.1(9.0-57.5) \\
17.3(6.0-35.0) \\
27.1(8.5-54.5) \\
37.9(11.0-74.0)\end{array}$ & $\begin{array}{l}26.8(9.0-53.0) \\
17.2(7.0-33.5) \\
27.3(9.5-53.5) \\
37.7(11.5-66.0)\end{array}$ & $\begin{array}{l}0.3(0.9) \\
0.1(1.0) \\
0.1(0.9) \\
0.3(2.4)\end{array}$ \\
\hline $\begin{array}{l}\text { ASBESTOSIS } \\
\text { Overall } \\
\text { Upper zones } \\
\text { Middle zones } \\
\text { Lower zones }\end{array}$ & $\begin{array}{l}18.3(8.5-32.5) \\
15.3(6.5-32.5) \\
20.1(9.0-42.0) \\
19.9(10.5-31.0)\end{array}$ & $\begin{array}{l}18.1(8.0-32.5) \\
15.7(7.0-33.0) \\
19.9(7.5-43.0) \\
20.3(9.5-31.0)\end{array}$ & $\begin{array}{l}0.3(0.4) \\
0.4(0.8) \\
0.2(0.3) \\
0.4(0.8)\end{array}$ \\
\hline
\end{tabular}


another scintiscan compiled seven minutes later, and in addition the technique only used $60 \%$ of the data from the lung fields and did not correct for bloodtissue background activity.

Our overall $\mathrm{T}^{1} 12 \mathrm{LB}$ values confirm earlier work showing accelerated solute clearance in interstitial lung disease $e^{69-11}$ and in otherwise healthy current smokers. ${ }^{121213}$ We have now shown that disturbances in pulmonary epithelial permeability in asbestosis, an interstitial lung disease characteristically confined radiologically to lower or lower plus middle zones, are widespread. This implies that radiographically normal areas have abnormal permeability. This finding accords with the observation that open lung biopsy in asbestosis may reveal disease when radiological changes are absent or, at most, equivocal. ${ }^{14}$

We found homogeneous distribution of clearance in most normal non-smokers. Rinderknecht and colleagues $^{9}$ found faster clearance in the upper zones in seated normal non-smokers and suggested that this may have been due to the distension of upper lobe alveoli by the weight of the lungs. We have not, however, observed differences in cephalocaudal distribution of solute clearance due to posture in normal non-smoking subjects.

We found that clearance is faster in the upper and middle zones in smokers. Mason and colleagues ${ }^{8}$ reported that clearance was faster in the upper zones, though they studied only selected areas rather than the whole lung field. Our findings are consistent with those of Pearson and colleagues, ${ }^{15}$ who studied 11 normal volunteers and demonstrated that during cigarette smoking technetium labelled sulphur colloid particles showed a shift of deposition towards the lung apices. They suggested that their observations offer a possible explanation for the apical localisation of centrilobular emphysema ${ }^{15}$; also of interest is the fact that bronchial carcinomas arise more frequently in the upper lobes. ${ }^{16}$

Our technique provides for correction for bloodtissue background activity without the added intervention and extra radiation dose of an intravenous injection of isotope. Correction for background activity is desirable; it augments the difference between normal and abnormal $\mathrm{T}^{1 / 2} \mathrm{LB}$ values because background counts form a higher proportion of counts over the lung fields when $T^{1 / 2} \mathrm{LB}$ is short than when it is long. The background correction without an intravenous injection is an approximation in that it does not take into account possible regional variation in background activity over the lung fields, perhaps reflecting differences in pulmonary blood flow. The background activity represents chest wall as well as pulmonary blood activity, however, and the close agreement between regional half times calculated by our method and by the method using an intravenous injection with separate background correction for each zone suggests that regional variations in background are not important.

The period of data acquisition affects the clearance half times obtained and the period chosen is arbitrary. ${ }^{17}$ Solute is cleared faster from abnormal lung and we have found that a short data acquisition time is adequate to identify the fast exponents that occur in some patients. Our results suggest that normal non-smokers usually show monoexponential clearance curves. Normal smokers may show two exponents, although the contribution of the fast component to overall clearance is usually small. Seven of the eight patients with asbestosis showed two exponents and the mean percentage contribution to overall clearance was greater than was observed in normal subjects and most smokers showing two exponents. The significance of finding that clearance curves can be resolved into two exponents is not clear. Some subjects with two exponents showed uniformly abnormal permeability throughout the lung zones while some with one exponent showed regional differences in permeability.

We have developed a non-invasive technique that allows qualitative and quantitative assessment to be made of regional disturbances in pulmonary epithelial permeability. Possibly the technique will provide further insight into the pathogenesis of interstitial lung diseases and smoking associated disorders.

ARG is supported by a grant from the Clinical Research Committee of the National Heart and Chest Hospitals.

\section{References}

1 Jones JG, Royston D, Minty BD. Changes in alveolar-capillary barrier function in animals and humans. Am Rev Respir Dis 1983;127:S51-9.

2 Jones JG, Minty BD, Royston D. The physiology of leaky lungs. Br J Anaesth 1982;54:705-21.

3 Pantin CFA, Britten A, Lawrence R, Sweatman M, Turner-Warwick M. Lung permeability in patients with interstitial lung diseuse. Thorax 1984;39:709 (abstract).

4 International Labour Office. Guidelines for the use of ILO international classification of radiographs of pneumoconioses. Occup. Saf. Hlth. Series No. 22 (Rev. 80) Geneva; ILO, 1980.

5 Cotes JE. Lung function assessment and application in medicine. 4th ed. Oxford: Blackwell, 1979.

6 Gellert AR, Winter RJD, Uthayakumar S, Langford JA, Rudd RM. Broncholaveolar lavage and clearance of ${ }^{99 \mathrm{~m}} \mathrm{Tc}$-DTPA in asbestosis. Thorax 1984;39:709 (abstract)

7 Gellert AR, Langford JA, Winter RJD, Uthayakumar S, Sinha G, Rudd RM. Asbestosis: assessment by 
bronchoalveolar lavage and measurement of pulmonary epithelial permeability. Thorax 1985;40:508-14.

8 Mason GR, Uszler JM, Effros RM, Reid E. Rapidly reversible alterations of pulmonary epithelial permeability induced by smoking. Chest 1983;83:6-11.

9 Rinderknecht J, Shapiro L, Krauthammer M, et al. Accelerated clearance of small solutes from the lungs in interstitial lung disease. Am Rev Respir Dis 1980;121:105-17.

10 Chopra SK, Taplin GV, Tashkin DP, Elam D. Lung clearance of soluble radioaerosols of different molecular weights in systemic sclerosis. Thorax 1979;34:63-7.

11 Jacobs MP, Baughman RP, Hughes J, Fernandez M. ${ }_{99} \mathrm{~m}$ Tc-DTPA aerosol scans in interstitial lung disease. Am Rev Respir Dis 1984;129:A52 (abstract).

12 Minty BD, Jordan C, Jones JG. Rapid improvement in abnormal pulmonary epithelial permeability after stopping cigarettes. Br Med J 1981;282:1183-6.
13 Jones JG, Lawler P, Crawley JCW, Minty BD, Hulands $\mathbf{G}$, Veall $\mathbf{N}$. Increased alveolar epithelial permeability in cigarette smokers. Lancet 1980;i:66-8.

14 Epler GR, McLoud TC, Gaensler EA, Mikus JP, Carrington CB. Normal chest roentgenograms in chronic diffuse infiltrative disease. $N$ Engl J Med 1978; 298:934-9.

15 Pearson MG, Vinitski S, Chamberlain MJ, Morgan WKC. Regional deposition of particles in the lung during cigarette smoking. Thorax 1984;39:716-7.

16 Spencer $\mathbf{H}$. Carcinoma of the lung. In: Spencer $\mathbf{H}$, ed. Pathology of the lung. Vol 1. 3rd ed. Oxford: Pergamon Press, 1977:773-854.

17 Oberdorster G, Utell MJ, Weber DA, Ivanovich M, Hyde RW, Morrow PE. Long clearance of inhaled ${ }^{99 m}$ Tc-DTPA in the dog. J Appl Physiol 1984; 57:589-95. 